\title{
Prevalence and antimicrobial resistance profile of Staphylococcus in dairy farms, abattoir and humans in Addis Ababa, Ethiopia
}

Takele Beyene ${ }^{1,2^{*}{ }^{\dagger}}$, Halefom Hayishe ${ }^{1}$, Fikru Gizaw ${ }^{3}$, Ashenafi Feyisa Beyi ${ }^{1,4{ }^{\dagger}}$, Fufa Abunna ${ }^{5}$, Bedaso Mammo ${ }^{6}$, Dinka Ayana ${ }^{7}$, Hika Waktole ${ }^{6}$ and Reta Duguma Abdi ${ }^{5,8+}$

\begin{abstract}
Background: Staphylococcus species cause mastitis and wound infection in livestock and food poisoning in humans through ingestion of contaminated foods, including meat and dairy products. They are evolving pathogens in that they readily acquire drug resistance, and multiple drug-resistant (MDR) isolates are increasing in human and veterinary healthcare. Therefore, this study was conducted to evaluate the prevalence of Staphylococci and their drug resistance in dairy farms and abattoir settings of Addis Ababa.
\end{abstract}

Methods: In this cross-sectional study, 193 samples of milk, meat, equipment and humans working in the dairy farms and abattoir were collected (dairy farms $=72$ and abattoir sources $=121$ ). Staphylococcus isolation and identification at the species level was done according to ISO-6888-3 using biochemical characteristics. An antimicrobial susceptibility test was conducted for 43 of the isolates using 15 antimicrobial agents commonly used for humans and livestock by the Kirby Bauer disk diffusion method following CLSI guidelines.

Results: Staphylococcus organism were isolated from 92 (47.7\%) of the total 193 samples, $50 \%$ in the dairy farms and $46.3 \%$ in the abattoir. The isolated species were S. aureus $(n=31 ; 16.1 \%)$, S. intermedius $(n=21 ; 10.9 \%)$, S. hyicus $(n=16 ; 8.3 \%)$, and coagulase negative Staphylococcus (CNS) $(n=24 ; 12.4 \%)$. Gentamycin was effective drug as all isolates $(n=43 ; 100 \%)$ were susceptible to it and followed by kanamycin $(n=39 ; 90.7 \%)$. However, the majority of the isolates showed resistance to penicillin-G (95.3\%), nalidixic acid (88.4\%), cloxacillin (79.1\%), vancomycin (65.1\%) and cefoxitin (55.8\%). Of the 15 S. aureus tested for drug susceptibility, $73.3 \%$ of them were phenotypically resistant to vancomycin (VRSA) and all of the 15 isolates showed multi-drug resistance (MDR) to $\geq 3$ drugs. Also, all of the tested CNS (100\%), S. hyicus (100\%) and the majority of S. intermedius isolates (88.9\%) developed MDR.

Conclusion: Alarmingly, the Staphylococcus isolates circulating in the dairy farms and abattoir in the study area harbor MDR. High level of Staphylococcus species isolation from personnel and equipment besides food (meat and milk) samples in dairy farms and abattoir settings reveals that the hygiene practice in the dairy farm and abattoir is substandard. Prudent drug use and improved hygienic practice is recommended in the dairy farms and abattoir to safeguard the public from the risk of acquiring infections and MDR pathogenic Staphylococcus.

Keywords: Abattoir, Antimicrobial susceptibility, Dairy farms, Food safety, Humans, Multi-drug resistance, Staphylococcus, VRSA

\footnotetext{
*Correspondence: takele.beyene@aau.edu.et

†Takele Beyene, Ashenafi Feyisa Beyi and Reta Duguma Abdi are contributed equally to this work

'Department of Biomedical Sciences, College of Veterinary Medicine and Agriculture, Addis Ababa University, Bishoftu, Ethiopia

Full list of author information is available at the end of the article
} 


\section{Background}

The genus Staphylococcus comprises of several species and subspecies [1]. The genus is broadly grouped into two, namely, coagulase- positive and coagulase-negative Staphylococcus (CNS) [2, 3]. CNS consists of a group of various Staphylococcus species that affect diverse host ranges. Some of them have evolved to cause mastitis in farm animals [4] whilst some species colonize post-surgical wounds (or cause infections in immunocompromised people) in humans [3]. Of the coagulase-positive Staphylococci group, the three major pathogenic ones are S. aureus, S. intermedius and S. hyicus [5, 6]. These three species are associated in many diverse and specialized forms with healthy and diseased farm animals and most of common pet animals [5]. They are the major pathogen causing mastitis although have tropism to different body parts of various hosts $[5,7,8]$. They are versatile pathogens with the ability to transfer between humans and livestock $[6,9,10]$. In human, they cause mild skin infection to more severe diseases such as pneumonia and septicemia [11]. In animals, their frequent involvement in mastitis results in contamination of milk and dairy products. They may found in a variety of locations in the dairy farms, abattoirs, food-processing units and on the body parts of the animals [12]. Staphylococci are also responsible for contamination of food products, food spoilage, reduction of food safety and shelf life and cause foodborne poisoning via production of deadly enterotoxins [13-17]. Infected individuals are the source of Staphylococci food contamination and intoxication at any point along the food chain [18]. Staphylococcal food poisoning has been reported as third cause of food-borne illnesses in the world [19].

Food is also an important vehicle for the transfer of antimicrobial resistant (AMR) factor to intestinal tract of consumers very efficiently $[20,21]$. AMR has become the main public health burden worldwide [22]. Further transfer of AMR bacteria to humans via the food chain [23] and from livestock has been well documented [8]. In this context, livestock, milk and meat may serve as reservoirs for human infections by AMR Staphylococcus strains, thus allowing these microorganisms to persist and spread in the community. Up to now, many researchers have focused on the spread of resistant $S$. aureus in clinical setting $[11,24]$. However, only handful of studies have been conducted about the presence of AMR in food animals in Ethiopia [25, 26] and moreover, S. intermedius, S. hyicus and CNS have been poorly studied. Multiple-drug resistant (MDR) staphylococcal isolates such as methicillinresistant $S$. aureus (MRSA) have been isolated primarily from human, and also from animal samples [27, 28]. A study conducted by Schmidt et al. [29] in the KwaZuluNatal province of South Africa have reported humans working with farm animals carry far more AMR Staphylococci than the farm animals they work with [29]. Thus, the transfer of AMR strains of Staphylococcus between humans and cows may result in serious health problems.

In Ethiopia, irrational antimicrobial use and misuse behavior is frequent [30], which could exacerbate the AMR issue in the country. The limited study on Staphylococcus species isolated from chicken-related samples in central and southern Ethiopia [31,32] and Salmonella from cattle-related samples in south-eastern Ethiopia [33] have reported an alarming level of MDR in both bacteria. However, a good estimate of the magnitude of the prevalence of Staphylococcus species and their AMR pattern for both human and animals are hardly available in Ethiopia. Therefore, the aims of this study were to (i) isolate and identify Staphylococcus species in dairy farms and slaughterhouses in Addis Ababa via sampling animals, food (milk and meat), farm and abattoir equipment and personnel, (ii) determine their prevalence distribution within farm and abattoir in different sample types, and (iii) evaluate antimicrobial susceptibility profile of Staphylococcus species.

\section{Methods}

\section{Study area and design}

This cross-sectional study was conducted from October 2013 to April 2014 at Addis Ababa, which is situated at latitude of $9^{\circ} 3^{\prime}$ and $38^{\circ} 43^{\prime}$ East [34]. Samples were collected from randomly selected dairy farms (dairy cows, farm personnel and dairy equipment) and Addis Ababa abattoir enterprise (slaughtered cattle, abattoir personnel and abattoir materials). Hygienic practices of the pre-milking, milking and post milking activities of dairy farms and pre-slaughtering, slaughtering and post slaughtering activities were assessed using a structured questionnaire.

\section{Sample types, collection, transportation and storage}

Overall, 193 samples were collected; samples from dairy farms included raw pooled udder milk $(\mathrm{n}=40)$, tank milk $(\mathrm{n}=8)$, pooled tank swabs $(\mathrm{n}=8)$, pooled bucket swabs $(\mathrm{n}=8)$ and pooled milkier hand swabs $(\mathrm{n}=8)$. From the abattoir carcass swabs $(n=103)$, pooled slaughter lines swab from hanging materials $(n=6)$, pooled knife swabs $(\mathrm{n}=6)$, pooled hand swabs $(\mathrm{n}=6)$ were collected.

Samples were collected aseptically from each critical point. Raw milk samples were collected from two critical points, from the cows' udder and milking bucket together with milkiers' hand and container swabs. The swabbing was done before milk sampling using sterile swabs. From the abattoir, a pooled carcass swab included neck, forelegs, thoracic, abdomen, and hind legs. In addition, the slaughter personnel's hands, surface of meat-cutting 
equipment and slaughter line were swabbed [35] and each swab was kept in a different material.

For every swab sample, a sterile single screw capped tube filled with $4 \mathrm{ml}$ of buffered peptone water (BPW) was used. Prior to sampling, swab tips were moistened in the BPW and during sampling, the swab was rotated and rubbed against the sampled surface several times. After completion of swabbing, the swab was placed inside a screw-capped tube containing BPW and transported using a cold chain to Microbiology laboratory of College of Veterinary Medicine and Agriculture, Addis Ababa University and stored at $+4{ }^{\circ} \mathrm{C}$ for a maximum of $24 \mathrm{~h}$ until it was cultured [35].

\section{Study methodology}

\section{Bacterial culture and species identification}

The techniques recommended by the International Organization for Standardization, ISO 6888-3: 2003 [35] was employed for the isolation and identification of Staphylococcus species from abattoir and farm samples. Final identification of Staphylococci organisms and species assignment were done based on Gram staining, hemolysis of blood agar, catalase test, sugar fermentation test, oxidase test, coagulase test, oxidation-fermentation test, and growth on mannitol salt agar and Purple agar base [35]. The biochemical test types used and the responses of Staphylococci species to the biochemical tests were summarized as shown in Table 1.

\section{Antimicrobial sensitivity test}

Disc diffusion testing was performed for Staphylococcal isolates in accordance with the Clinical and Laboratory Standards Institute (CLSI) (2008) [36]. One representative antimicrobial agent from each subclass of commonly used antimicrobials for treatment of bovine mastitis or considered as important antimicrobial agents for human was selected for susceptibility testing. The phenotypic antimicrobial sensitivity response of each isolate was evaluated using panel of 15 antimicrobial discs. The used antimicrobial agents included $15 \mu \mathrm{g}$ erythromycin (E), $10 \mu \mathrm{g}$ streptomycin (S), $50 \mu \mathrm{g}$ nitrofurantoin (F), 10 unit penicillin-G (P), $5 \mu \mathrm{g}$ ciprofloxacin (CIP), $25 \mu \mathrm{g}$ sulfamethoxazole-trimethoprim (SXT), $5 \mu \mathrm{g}$ cloxacillin (OB), $30 \mu \mathrm{g}$ cefoxitin (FOX), $30 \mu \mathrm{g}$ chloramphenicol (C), $30 \mu \mathrm{g}$ tetracycline (TE), $10 \mu \mathrm{g}$ gentamycin $(\mathrm{CN}), 30 \mu \mathrm{g}$ vancomycin (VA), $30 \mu \mathrm{g}$ kanamycin (K), $30 \mu \mathrm{g}$ amoxicillin (AML), and $30 \mu \mathrm{g}$ nalidixic acid (NA). All the discs were purchased from Oxoid, UK. The diameters of the zone of inhibition around the disks were measured to the nearest millimeter using rulers. The isolates were classified as susceptible, intermediate and resistant according to the interpretative standards of CLSI (2008) [36]. Isolates showing resistance to three or more antimicrobial subclass were considered as multiple drug resistant (MDR) [37].

\section{Data analysis}

Data was analyzed using SPSS software package (SPSS 20.0 for window 7, SPSS Inc, Chicago, Illinois). The proportions of Staphylococcus isolates in samples from the abattoir and dairy farms were computed. The Chi square $\left(x^{2}\right)$ test was used to determine the difference in proportions of Staphylococcus among different sample types and sources. The significance level of $\alpha=0.05$ was taken as a cut-off value.

\section{Results}

Our personal observation during sample collection showed that dairy farms and abattoir workers practiced substandard hygiene. The number of Staphylococcus species isolated from personnel and equipment in dairy farms and abattoir was presented in Table 2.

Out of 193 samples, Staphylococci were isolated from $92(47.7 \%)$ samples, 36 from the dairy farms and 56 from the abattoir. The proportion of Staphylococcus isolates in the sample sources and types varied, but not significant $(\mathrm{P}>0.05)$. Based on the biochemical tests, the predominant species was $S$. aureus $(\mathrm{n}=31 ; 16.1 \%)$, followed by CNS $(\mathrm{n}=24 ; 12.4 \%)$, S. intermedius $(\mathrm{n}=21 ; 10.9 \%)$ and S. hyicus $(\mathrm{n}=16 ; 8.3 \%)$ (Table 2$)$.

Table 1 Differential tests used for identification of Staphylococcus species and their reactions

\begin{tabular}{|c|c|c|c|c|c|c|c|c|c|}
\hline \multirow[t]{2}{*}{$\begin{array}{l}\text { Staphylococcus } \\
\text { species }\end{array}$} & \multirow[t]{2}{*}{ Hemolysis } & \multirow[t]{2}{*}{$\begin{array}{l}\text { Pigment } \\
\text { production }\end{array}$} & \multirow[t]{2}{*}{$\begin{array}{l}\text { Gram } \\
\text { stain }\end{array}$} & \multirow[t]{2}{*}{$\begin{array}{l}\text { Coagulase } \\
\text { test }\end{array}$} & \multirow[t]{2}{*}{$\begin{array}{l}\text { Catalase } \\
\text { test }\end{array}$} & \multirow[t]{2}{*}{ OF test } & \multicolumn{2}{|c|}{$\begin{array}{l}\text { Fermentation } \\
\text { of sugar }\end{array}$} & \multirow{2}{*}{$\begin{array}{l}\text { Susceptibility to } \\
\text { polymyxin B } \\
\text { (300 unit) }\end{array}$} \\
\hline & & & & & & & MSA & PAB & \\
\hline S. aureus & + & + & + & + & + & $\mathrm{F}$ & + & + & $\mathrm{R}$ \\
\hline S. intermidius & + & - & + & + & + & $\mathrm{F}$ & \pm & \pm & S \\
\hline S. hyicus & - & - & + & + & + & $\mathrm{F}$ & - & - & $\mathrm{R}$ \\
\hline CNS & - & - & + & - & + & $\mathrm{F}$ & - & - & NP \\
\hline
\end{tabular}

,$+ 90 \%$ or more strains are positive;, $\pm 90 \%$ or more strains are weakly positive;,$- 90 \%$ or more strains are negative CNS coagulase negative staphylococcus, F fermentative, OF oxidation-fermentation, MSA mannitol salt agar, $P A B$ Purple agar base, $R$ resistant, $S$ susceptible, NP not performed 
Table 2 Proportions of Staphylococcus species isolated $(n=92)$ from dairy farms and abattoirs in Addis Ababa, Ethiopia

\begin{tabular}{|c|c|c|c|c|c|c|}
\hline Sample source & Sample type & S. aureus N (\%) & S. intermedius N (\%) & S. hyicus N (\%) & CNS N (\%) & Total N (\%) \\
\hline \multirow[t]{4}{*}{ Abattoir } & AHS & $0(0.0)$ & $0(0.0)$ & $0(0.0)$ & $1(16.7)$ & $1(16.7)$ \\
\hline & KS & $2(33.3)$ & $2(33.3)$ & $1(16.7)$ & $0(0.0)$ & $5(83.3)$ \\
\hline & SLS & $2(33.3)$ & $0(0.0)$ & $0(0.0)$ & $3(50.0)$ & $5(83.3)$ \\
\hline & CS & $12(11.7)$ & $13(12.6)$ & $9(8.7)$ & $11(10.7)$ & $45(43.7)$ \\
\hline \multirow[t]{7}{*}{ Farm } & BS & $2(25.0)$ & $0(0.0)$ & $0(0.0)$ & $1(12.5)$ & $3(37.5)$ \\
\hline & FHS & $2(25.0)$ & $1(12.5)$ & $1(12.5)$ & $1(12.5)$ & $5(62.5)$ \\
\hline & TM & $2(25.0)$ & $0(0.0)$ & $1(12.5)$ & $1(12.5)$ & $4(50.0)$ \\
\hline & TS & $1(12.5)$ & $1(12.5)$ & $0(0.0)$ & $2(25.0)$ & $4(50.0)$ \\
\hline & UM & $8(20.0)$ & $4(10.0)$ & $4(10.0)$ & $4(10.0)$ & $20(50.0)$ \\
\hline & Total & $31(16.1)$ & $21(10.9)$ & $16(8.3)$ & $24(12.4)$ & $92(47.7)$ \\
\hline & $x^{2}$ (P value) & $7.2(0.5)$ & $6.9(0.5)$ & $3.6(0.9)$ & $10.4(0.2)$ & $10.2(0.2)$ \\
\hline
\end{tabular}

AHS hand swab from abattoir, CNS coagulase negative Staphylococcus, KS knives swab, SLS slaughter line swab, CS carcass swab, BS bucket swab, FHS hand swabs from farm, TM tanks milk, TS tanks swab, UM udder milk, $N$ number

\section{Staphylococcus isolates from dairy farm}

The $36(50.0 \%)$ isolates identified as Staphylococci species from dairy settings were tested for species assignment using biochemical characteristics. The majority of them were $S$. aureus ( $\mathrm{n}=15 ; 20.8 \%)$, followed by CNS $(\mathrm{n}=9 ; 12.5 \%)$, S. intermedius $(\mathrm{n}=6 ; 8.3 \%)$ and $S$. hyicus $(\mathrm{n}=6 ; 8.3 \%)$. The frequency of isolation of Staphylococcus varied between sample types and ranged from 37.5 to $62.5 \%$. Highest prevalence was observed in milkier hand swabs (62.5\%), however, the difference was not significant (P > 0.05) (Table 2).

\section{Staphylococcus isolates from abattoir}

As indicated above from 121 abattoir source samples, 56 (46.3\%) isolates of Staphylococcus species were isolated. These isolates were grouped by biochemical test into $S$. aureus $(\mathrm{n}=16 ; 13.2 \%)$, CNS $(\mathrm{n}=15 ; 12.4 \%)$, S. intermedius $(\mathrm{n}=15 ; 12.4 \%)$, and $S$. hyicus $(\mathrm{n}=10 ; 8.3 \%)$. The frequency of isolation of Staphylococcus varied between sample types and ranged from 16.7 to $83.3 \%$. The results showed a comparatively higher prevalence in knife and slaughter hanging material swabs, each with $83.3 \%$. This difference was statistically significant $(\mathrm{P}<0.05)$.

\section{Staphylococcus isolates from personnel}

Staphylococcus was isolated from 14 hand swabs from dairy farm workers $(\mathrm{n}=8)$ and abattoir workers $(\mathrm{n}=6)$. Staphylococcus species was isolated from six (42.9\%) hand swab samples. The six isolates identified using biochemical characteristics as $S$. aureus $(\mathrm{n}=2 ; 14.3 \%)$, CNS ( $\mathrm{n}=2 ; 14.3 \%)$, S. intermedius ( $\mathrm{n}=1 ; 7.1 \%)$, and S. hyicus $(\mathrm{n}=1 ; 7.1 \%)$. The results showed a relatively higher prevalence in farm milkier hand swab having five $(83.3 \%)$ compared to the one isolate $(16.7 \%)$ from abattoir workers' hand swab. However, the difference was not statistically significant $(\mathrm{P}>0.05)$.

\section{Antimicrobial susceptibility testing}

Overall, antimicrobial susceptibility test was performed on 43 Staphylococcus isolates. Eighteen (41.9\%) isolates were from farms and 25 (58.1\%) from abattoir. The 43 isolates tested comprised of S. aureus ( $\mathrm{n}=15 ; 34.9 \%)$, CNS ( $\mathrm{n}=13 ; 30.2 \%)$, S. intermedius ( $\mathrm{n}=9 ; 20.9 \%)$, and S. hyicus $(\mathrm{n}=6 ; 14.0 \%)$. Penicillin-G $(\mathrm{P})$ resistance was the highest widespread resistance recorded among the isolates in this study ( $\mathrm{n}=41$ isolates; $95.3 \%)$, followed by NA 38 (88.4\%), OB 34 (79.1\%), VA 28 (65.1\%) and FOX 24 (55.8\%). Conversely, lower resistance was recorded against $\mathrm{K}$ with 39 (90.7\%) susceptible and four (9.3\%) intermediates (Table 3). Of the 15 antibiotics tested, $\mathrm{CN}$ was currently the most effective drug as all of the 43 (100.0\%) isolates were susceptible. Among the isolates resistant to VA, S. aureus and CNS contributed for $39.3 \%$ $(11 / 28)$ and $32.1 \%(9 / 28)$, respectively.

In this study, all of the $S$. aureus ( $\mathrm{n}=15 ; 100 \%)$, CNS $(\mathrm{n}=13 ; 100 \%)$ and S. hyicus $(\mathrm{n}=6 ; 100 \%)$ isolates exhibited MDR as each isolate at least resistant to $\geq 3$ drugs simultaneously. Among the nine $S$. intermedius isolates tested, $8(88.9 \%)$ of them exhibited MDR. Alarmingly, some isolates of Staphylococcus species demonstrated resistance to 13 different antimicrobial subclasses (MDR) at a time as shown in Table 4. The comparison of AMR patterns among various sample types showed there was not statistically significant differences $(\mathrm{P}>0.05)$.

\section{Discussion}

Both coagulase-positive Staphylococci and CNS are commensal opportunistic infections of animals and humans [38]. They cause superficial skin infection, mastitis and severe invasive diseases in farm animals and wound infections in humans $[3,5]$. They are also well known for their food poisoning via their enterotoxins [9, 1317] and for their ability to acquire AMR [38]. However, 
Table 3 Antimicrobial susceptibility profile of Staphylococcus isolates $(n=43)$ from dairy farms and abattoir in Addis Ababa, Ethiopia

\begin{tabular}{lccc}
\hline Drug & Susceptible N (\%) & Intermediate N (\%) & Resistant N (\%) \\
\hline Amoxicillin (AML) & $33(76.7)$ & $0(0.0)$ & $10(23.3)$ \\
Cefoxitin (FOX) & $19(44.2)$ & $0(0.0)$ & $24(55.8)$ \\
Chloramphenicol (C) & $27(62.8)$ & $6(14.0)$ & $10(23.3)$ \\
Ciprofloxacin (CIP) & $37(85.0)$ & $5(11.6)$ & $1(2.3)$ \\
Cloxacillin (OB) & $9(20.9)$ & $0(0.0)$ & $34(79.1)$ \\
Erythromycin (E) & $14(32.6)$ & $9(20.9)$ & $20(46.5)$ \\
Gentamicin (CN) & $43(100.0)$ & $0(0.0)$ & $0(0.0)$ \\
Kanamycin (K) & $39(90.7)$ & $4(9.3)$ & $0(0.0)$ \\
Nalidixic acid (NA) & $4(9.3)$ & $1(2.3)$ & $38(88.4)$ \\
Nitrofurantoin (F) & $14(32.6)$ & $8(18.6)$ & $21(48.8)$ \\
Penicillin-G (P) & $2(4.7)$ & $0(0.0)$ & $41(95.3)$ \\
Streptomycin (S) & $29(67.4)$ & $7(16.3)$ & $7(16.3)$ \\
Sulfamethoxazole-trimethoprim (SXT) & $1(2.3)$ & $9(20.9)$ \\
Tetracycline (TE) & $33(76.7)$ & $2(4.6)$ & $15(34.9)$ \\
Vancomycin (VA) & $26(60.5)$ & $0(0.0)$ & $28(65.1)$ \\
\hline
\end{tabular}

Key: $N$ number

Table 4 Multiple drug-resistance profile of Staphylococci isolates

\begin{tabular}{|c|c|c|c|c|c|c|}
\hline \multirow{2}{*}{$\begin{array}{l}\text { Number of drugs } \\
\text { showing resistance }\end{array}$} & \multirow[t]{2}{*}{ Frequency } & \multicolumn{4}{|c|}{ Number and $\%$ of } & \multirow[t]{2}{*}{ Total \% } \\
\hline & & S. aureus & S. intermedius & S. hyicus & CNS & \\
\hline 0 & 1 & $0(0.0)$ & $1(11.1)$ & $0(0.0)$ & $0(0.0)$ & 2.3 \\
\hline 3 & 3 & $1(6.7)$ & $1(11.1)$ & $1(16.7)$ & $0(0.0)$ & 7.0 \\
\hline 4 & 5 & $3(20.0)$ & $1(11.1)$ & $0(0.0)$ & $1(7.7)$ & 11.6 \\
\hline 5 & 9 & $4(26.7)$ & $2(22.2)$ & $2(33.3)$ & $1(7.7)$ & 20.9 \\
\hline 6 & 8 & $2(13.3)$ & $2(22.2)$ & $1(16.7)$ & $3(23.1)$ & 18.6 \\
\hline 7 & 7 & $2(13.3)$ & $0(0.0)$ & $1(16.7)$ & $4(30.8)$ & 16.3 \\
\hline 8 & 5 & $2(13.3)$ & $1(11.1)$ & $0(0.0)$ & $2(15.4)$ & 11.6 \\
\hline 9 & 3 & $1(6.7)$ & $0(0.0)$ & $1(16.7)$ & $1(7.7)$ & 7.0 \\
\hline 10 & 1 & $0(0.0)$ & $0(0.0)$ & $0(0.0)$ & $1(7.7)$ & 2.3 \\
\hline 13 & 1 & $0(0.0)$ & $1(11.1)$ & $0(0.0)$ & $0(0.0)$ & 2.3 \\
\hline Total & 43 & $15(100)$ & $9(100)$ & $6(100)$ & $13(100)$ & 100 \\
\hline$\%$ with MDR & & $15(34.9)$ & $8(18.6)$ & $6(14.0)$ & $13(30.2)$ & $97.7(100)$ \\
\hline$X^{2}$ (P value) & & $3.89(0.91)$ & $10.84(0.287)$ & $4.51(0.875)$ & $9.13(0.426)$ & \\
\hline
\end{tabular}

CNS coagulase negative Staphylococcus, MDR multiple drug-resistance

a good estimate of the magnitude of the prevalence of Staphylococcus species and their AMR pattern in different livestock production settings, in foods of livestock origin, and in humans involved in handling of the foods are poorly available in Ethiopia. Therefore, this study was conducted to evaluate the prevalence of Staphylococci and their drug resistance in dairy farms and abattoir settings of Addis Ababa.

In this study, the overall prevalence of Staphylococci was $47.7 \%$ of 193 tested samples collected from dairy farm and abattoir settings, suggesting the significant association of Staphylococci species with livestock. The Staphylococci prevalence was higher at both dairy farm (50.0\%) and abattoir (46.3\%) settings. The substandard hygienic practices during pre-milking, milking and post milking activities in dairy farms might have contributed. Milk hygiene and udder-cleaning operation was insufficiently conducted in Ethiopia triggering flare up of mastitis [39]. In this regard, poor pre-milking udder preparations could play an important part in the contamination of milk during milking [40, 41]. Similarly, poor hygienic practice was noticed in pre-slaughtering, 
slaughtering and post slaughtering activities within the abattoir during this study. In this regards, $15.4 \%$ of the abattoir workers had no health certificate and $11.3 \%$ of the butchers did not use protective clothes. There was no hot water, sterilizer and cooling facility in the abattoir in Ethiopia [42].

The higher prevalence of Staphylococci at both dairy farm and abattoir settings in this study, indicating its (i) serious economic, animal welfare, food safety and public health problem and (ii) association to livestock for its transmission between animals and humans in livestock farm setting. Similar findings in its association with livestock have been reported from elsewhere [43, 44]. The predominant Staphylococci species detected in this study were $S$. aureus (16.1\%), followed by CNS (12.4\%), S. intermedius (10.9\%), and S. hyicus (8.3\%). These four Staphylococci species group are said to be the most pathogenic [5]. Furthermore, some animal-associated clones within these species group appear to have the capacity to colonize and cause disease in multiple host species [45]. They are versatile pathogens with the ability to transfer between humans and different livestock $[6,9,10]$ with a possible switch from one-to-another host species [44, 46].

The Staphylococci species resilience characteristics might be revealed in their ability to appear in a variety of locations in this study. In this regard, we isolated them from bucket swab (37.5\%), tanks swab (50.0\%), tanks milk (50.0\%), udder milk (50.0\%), and milkier hand swabs $(62.5 \%)$ in diary settings. We also isolated them from carcass meat (43.7\%), abattoir workers' hand (16.7\%), knife $(83.3 \%)$ and slaughter hanging material (83.3\%) in abattoir settings. Interestingly, $16.7 \%$ of abattoir workers and $83.3 \%$ of milkier personnel carry Staphylococci in their hand. It has been reported that about one-third of humans carry Staphylococci in their nasal cavity [46]. Thus, frequently washing of the abattoir slaughterers hand could be the possible factor responsible for the relatively low prevalence of Staphylococcus in abattoir. In this study, Staphylococcus isolates were isolated more from carcass meat swab from slaughtered cattle than any other samples. This could be attributed to the higher sample size of the carcass meat samples than others. The higher number of personnel workers at abattoir might have also contributed to carcass contamination. In general, our result revealed the substandard milk and meat hygiene and personnel and equipment hygiene practices in dairy farms and abattoirs during handling, storage and processing of foods of livestock origin. Our finding agrees with the previous report from dairy farms, slaughterhouses, food-processing units and on the body parts of the animals and humans [12, 47]. For example, $S$. aureus (13.2\%), CNS (12.4\%), S. intermedius (12.4\%), and
S. hyicus (8.3\%) were isolated from abattoir including carcass meat. Isolation of these Staphylococci species from meat demonstrated that they have entered the food chain to affect the food safety and public health $[48,49]$. Contamination of milk and meat by them could lead to food poisoning through production of Staphylococcal enterotoxins. Available literature indicated that $62.9 \%$ of isolates from sheep milk [50] and $15-55.9 \%$ of isolates from dairy products $[16,51-53]$ produce enterotoxin with marked geographical differences. Although this is beyond the scope of our paper, the culture of raw milk and raw meat consumption in Ethiopia might be potential sources of Staphylococcal enterotoxin food poisonings to the public.

The prevalence of $S$. aureus in 193 tested samples was $31(16.1 \%)$. S. aureus was isolated from nearly all sample types with different proportion, but not from abattoir slaughter worker's hand swab $(0.0 \%)$. This finding is similar with the $17.2 \%$ prevalence in Egypt [54] and $19.5 \%$ from human and animal sources [55], but lower than $75 \%$ in bovine bulk milks [56], 68\% [14], 61.3\% [57], $40 \%$ [58] and $82.2 \%$ from cheeses made from raw cow's milk [59]. The $10.9 \%$ S. intermedius prevalence detected in our study was similar with the $13 \%$ in cheese samples [59] but higher than the $2 \%$ in milk and milk product samples [58]. Similarly, the prevalence of S. hyicus was $8.3 \%$ in our study. Almost half of the total isolates were isolated from carcass swab. It was higher than the $4 \%$ in milk and milk product samples [58] and $4.5 \%$ in cheeses [59]. CNS was the second most isolated species next to $S$. aureus in this study. It was isolated from almost all the samples except in knife swab. The predominant proportion of CNS was isolated from carcass swab. The overall prevalence of CNS was $12.4 \%$, which was lower than the $54 \%$ in raw milk of cattle in Mongolia [60] and 29\% [59]. The high number of CNS isolation in the current study may be indicator for poor hygienic practices in the dairy farms and abattoir. CNS is a part of the normal teat skin flora, mucosa of humans and animals, and also found free living in the environment $[61,62]$. In the past, CNS was often regarded as skin flora opportunists. However, recent data indicate that they are associated with several subclinical and clinical infections [63].

Of 43 isolates, $42(97.7 \%)$ had resistance to at least one of the 15 antimicrobials tested. It had been reported that about $90 \%$ of $S$. aureus isolated from patients was found resistant in 1980s [64]. The antimicrobials we currently evaluated could be subjectively classified into four based on magnitude of resistance recorded in this study. These include (i) highly effective antimicrobials where all isolates were susceptible, (ii) effective antimicrobials as $>95 \%$ isolates were susceptible, (iii) still usable antimicrobials as $>50 \%$ of isolates were susceptible, and (iv) not recommended for use as $>55 \%$ of the isolates were 
resistant. In this regard, the general drug use policy recommends antimicrobials for use especially for treatment of infection in humans only if less than half $(<55 \%)$ of the isolates are resistant [65].

Accordingly, $\mathrm{CN}$ and $\mathrm{K}$ are the most effective antimicrobials as all of the 43 Staphylococci isolates were susceptible to both in this study. In fact, four (9.3\%) of the 43 isolates had intermediate breakpoint response to $\mathrm{K}$. Our finding was similar to earlier studies in other countries $[55,66,67]$. Few isolates had resistance to CIP $(2.3 \%)$, thus, fits to the second antimicrobial category listed above. Third, resistant among isolates ranges between 16.3 and $48.8 \%$ for some antimicrobials in this study. Antimicrobials in this group include S (16.3\%), SXT (20.9\%), AML (23.3\%), C (23.3\%), TE (34.9\%), E (46.5\%), and $\mathrm{F}(48.8 \%)$. Our finding is comparable to the findings of others [26], but contrary to the findings in Taiwan [47]. Fourth, $>55 \%$ of the Staphylococci isolates had resistance to cefoxitin (55.8\%), VA (65.1\%), OB (79.1\%), NA (88.4\%), and $\mathrm{P}$ (95.3\%). The resistance value recorded to $\mathrm{P}$ (95.3\%) was the highest in this study. In another study in different geographical areas showed that it was $87.2 \%$ in Ethiopia [68], 80\% in Sweden [69], 57\% in Iran [70], 50\% in Finland [71], and 23\% in West India [72]. In a separate study, $70-73 \%$ of $S$. aureus strains isolated from various foods were resistant to $\beta$-lactam such as $P$ and ampicillin [73]. Penicillin (P) and other $\beta$-lactam antibiotics are the most commonly used antimicrobials for the treatment of infection of mastitis in veterinary practice in Ethiopia [64]. The higher prevalence of penicillin resistant isolate could be, therefore, related to prolonged, improper and indiscriminate usage as suggested by some authors [64, 74].

Overall, all (100\%) of S. aureus, CNS, and S. hyicus (whilst $88.9 \%$ of $S$. intermedius) isolates had resistance to $\geq 3$ antimicrobials (MDR) of all the tested drugs. The share of MDR isolate by Staphylococci species among 43 isolates was $34.9 \%$ S. aureus, $30.2 \%$ CNS, $20.9 \%$ S. intermedius, and $14.0 \%$ S. hyicus (Table 3) although it was not significantly different between Staphylococcus species. Most of MDR was primarily due to P, NA, OB, VA and FOX in this study. This finding is higher than the study result of Moon et al. [75] who reported that about two out of $21 \mathrm{~S}$. aureus has been reported to be resistant to $\geq 3$ of non- $\beta$-lactam antimicrobials including $P$ and $E$ [75]. Furthermore, higher MDR was observed in our study than (79\%) among isolates reported in Korea [76] and at Jimma Hospital, Ethiopia (80\%) [77]. The abundance of MDR Staphylococci isolated from milk (farm), meat (abattoir), equipment and humans could pose a risk to public health. Transfer of antimicrobial resistant bacteria to humans has been reported via the food chain [23] and from livestock [8]. AMR is a major public health burden worldwide [22]. Staphylococcus strains have developed
MDR worldwide with broad diversity in prevalence rate in different regions [37].

\section{Conclusions}

The present study revealed high proportion of Staphylococcus species (47.7\%) (S. aureus, S. intermedius, S. hyicus and CNS) in dairy farms and abattoir settings at Addis Ababa. Higher proportion of isolation rate of Staphylococcus species from farm and abattoir personnel signals the existence of poor hygienic practices and consequently, its public health implication. All the tested isolates for antimicrobial susceptibility showed resistance to at least three antimicrobial agents except one S. intermidius isolate susceptible to all tested drugs. The isolates also showed good susceptibility profile to $\mathrm{CN}, \mathrm{K}$, and CIP, but resistance was observed against $\mathrm{P}, \mathrm{NA}, \mathrm{OB}, \mathrm{VA}$ and FOX. Moreover, MDR was also observed against some of the commonly used antimicrobial agents. Thus, improving hygienic measures in the dairy farms as well as within the abattoir must be effected to safeguard the public from risk of staphylococcal food poisoning and acquiring MDR isolates. Additionally, future research should consider identifying Staphylococcus enterotoxins from milk and meat and genes responsible for AMR in Ethiopia.

\section{Abbreviations \\ AML: amoxicillin; AMR: antimicrobial resistance; BAP: blood agar plates; BPW: buffer peptone water; C: chloramphenicol; CFU: colony forming units; $\mathrm{Cl}$ : confidence interval; CIP: ciprofloxacin; CN: gentamycin; CNS: coagulase- negative Staphylococcus; E: erythromycin; ELFA: enzyme-linked fluorescent assay; F: nitrofurantoin; FOX: cefoxitin; ISO: International standard organiza- tion; K: kanamycin; MSA: mannitol salt agar; $\mu$ m: micrometer; MDR: multidrug resistance; $\mathrm{NA}$ : nalidixic acid; $\mathrm{NaCl}$ : sodium chloride; NAP: nutrient agar plates; OB: cloxacillin; P: penicillin-G; PAB: Purple agar base; S: streptomycin; SEs: Staphylococcal enterotoxins; SXT: sulfamethoxazole-trimethoprim; TE: tetracy- cline; TSB: tryptone soya broth; VA: vancomycin; VRSA: vancomycin resistant Staphylococcus aureus.}

\section{Authors' contributions}

RDA, AFB, FA and TB developed the research idea. HH and FG contributed to collecting the materials. TB, FA, AFB, DA and RDA coordinated and supervised the study. TB, HH, and FG conducted laboratory investigations. TB, FG, FA, $A F B, B M, H W$ and RDA provided valuable information on the subject of data analysis and the design of the study. TB and $\mathrm{HH}$ drafted the manuscript. TB, AFB and RDA revised the manuscript. All authors read and approved the final manuscript.

\footnotetext{
Author details

${ }^{1}$ Department of Biomedical Sciences, College of Veterinary Medicine and Agriculture, Addis Ababa University, Bishoftu, Ethiopia. ${ }^{2}$ Department of Pharmacology and Clinical Pharmacy, College of Health Sciences, Addis Ababa University, Addis Ababa, Ethiopia. ${ }^{3}$ School of Veterinary Medicine, Samara University, Samara, Ethiopia. ${ }^{4}$ Department of Animal Sciences, University of Florida, Gainesville, FL, USA. ${ }^{5}$ Department of Clinical Studies, College of Veterinary Medicine and Agriculture, Addis Ababa University, Bishoftu, Ethiopia. ${ }^{6}$ Department of Microbiology, Immunology and Veterinary Public Health, College of Veterinary Medicine and Agriculture, Addis Ababa University, Bishoftu, Ethiopia. ${ }^{7}$ Department of Veterinary parasitology and pathology, College of Veterinary Medicine and Agriculture, Addis Ababa University, Bishoftu, Ethiopia. ${ }^{8}$ Department of Animal Sciences, University of Tennessee, Knoxville, TN, USA
} 


\section{Acknowledgements}

This study was funded by Addis Ababa University. The support of the Addis Ababa abattoir enterprise, dairy farm owners and individuals working in the study dairy farms and abattoir is appreciated.

\section{Competing interests}

The authors declare that they have no competing interests.

\section{Availability of data and materials}

All data generated or analyzed during this study are included in the "Result".

\section{Ethics approval and consent to participate}

This study was granted an ethical approval from the College of Veterinary Medicine and Agriculture Institutional Research and Review Committee. Human samples were collected following prior explanation of the objectives of the study to the farm workers, and sampled based on their consent. Confidentiality of the participants was maintained using unique code.

\section{Funding}

Addis Ababa University provided fund for this study.

\section{Publisher's Note}

Springer Nature remains neutral with regard to jurisdictional claims in published maps and institutional affiliations.

\section{Received: 8 January 2016 Accepted: 20 April 2017}

Published online: 28 April 2017

\section{References}

1. Kwok AY, Chow AW. Phylogenetic study of Staphylococcus and Macrococcus species based on partial hsp60 gene sequences. Int J Syst Evolut Microbiol. 2003;53(1):87-92.

2. Sasaki T, Tsubakishita S, TanakaY Sakusabe A, Ohtsuka M, Hirotaki S, et al. Multiplex-PCR method for species identification of coagulase-positive staphylococci. J Clin Microbiol. 2010:48(3):765-9.

3. Becker K, Heilmann C, Peters G. Coagulase-negative staphylococci. Clin Microbiol Rev. 2014;27(4):870-926.

4. Pyörälä S, Taponen S. Coagulase-negative staphylococci-emerging mastitis pathogens. Vet Microbiol. 2009;134(1):3-8.

5. Devriese LA. Staphylococci in healthy and diseased animals. J Appl Bacteriol. 1990;19:71S-80S.

6. Tanner MA, Everett CL, Youvan DC. Molecular phylogenetic evidence for noninvasive zoonotic transmission of Staphylococcus intermedius from a canine pet to a human. J Clin Microbiol. 2000;38(4):1628-31.

7. Oliver S, Jayarao B, Almeida R. Food borne pathogens in milk and the dairy farm environment food safety and public health implications. Foodbourne Pathog Dis. 2005;2:115-29.

8. Graveland H, Duim B, Van Duijkeren E, Heederik D, Wagenaar JA. Livestock-associated methicillin-resistant Staphylococcus aureus in animals and humans. Int J Med Microbiol. 2011;301(8):630-4

9. Takeuchi S, Kobayashi Y, Morozumi T, Niibori S. Isolation and some properties of Staphylococcus hyicus subsp. hyicus from pigs, chickens and cows. Jpn J Vet Sci. 1985:47(5):841-3.

10. Zadoks R, Van Leeuwen H, Barkema O, Sampimon H, Verbrugh Y, Schukken $\mathrm{H}$, et al. Application of pulsed-field gel electrophoresis and binary typing as tools in veterinary clinical microbiology and molecular epidemiologic analysis of bovine and human Staphylococcus aureus isolates. J Clin Microbiol. 2000;38:1931-9.

11. Ateba C, Mbewe M, Moneoang M, Bezuidenhout C. Antibiotic resistant Staphylococcus aureus isolated from milk in the Mafikeng Area, North West province South Africa. S Afr J Sci. 2010;106:12-3.

12. Roberson JR, Fox LK, Hancock DD, Gay JM, Besser TE. Ecology of Staphylococcus aureus isolated from various sites on dairy farms 1. J Dairy Sci. 1994:77(11):3354-64.

13. Adesiyun AA, Tatini SR, Hoover DG. Production of enterotoxin (s) by Staphylococcus hyicus. Vet Microbiol. 1984;9(5):487-95.
14. Loir Y, Baron F, Gautier M. Staphylococcus aureus and food poisoning. Genet Mol Res. 2003;2:63-76.

15. Rho M, Schaffner D. Microbial risk assessment of staphylococcal food poisoning. J Food Microbiol. 2007;116:332-8.

16. Smith K. Food borne pathogenic microorganisms and natural toxins. Food and Drug Administration. Center Food Safety. Appl Nutr. 2007;10:119-50.

17. Hennekinne JA, De Buyser ML, Dragacci S. Staphylococcus aureus and its food poisoning toxins: characterization and outbreak investigation. FEMS Microbiol Rev. 2012;36(4):815-36.

18. Institute of Food Technologists (IFT). Bacteria associated with foodborne diseases. Scientific status summary. The Society for Food Science and Technology; 2004. http://www.ift.org/Knowledge-Center/Read-IFTPublications/Science-Reports/Scientific-Status-Summaries/BacteriaAssociated-with-Foodborne-Diseases.aspx. Accessed 16 Feb 2017.

19. Alharbi A, Ibrahim ASS, Al-Salamah AA. Prevalence of various enterotoxins among clinical Staphylococcus aureus strains isolated from food borne poisoning patients. J Pure Appl Microbiol. 2014;8(4):379-88.

20. Sørum H, L'Abée-Lund TM. Antibiotic resistance in food-related bacteria-a result of interfering with the global web of bacterial genetics. Int J Food Microbiol. 2002;78(1):43-56

21. Pesavento G, Ducci B, Comodo N, Nostro AL. Antimicrobial resistance profile of Staphylococcus aureus isolated from raw meat: a research for methicillin resistant Staphylococcus aureus (MRSA). Food Control. 2007;18(3):196-200

22. Thirapatsakun T. Mastitis management. In: Hunt, Chantalakhana, editors. Small holder dairying in the tropics. Nairobi: ILRl; 1999. p. 299-339.

23. Angulo F, Nargund V, Chiller T. Evidence of an association between use of antimicrobial agents in food animals and antimicrobial resistance among bacteria isolated from humans and human health consequences of such resistance. J Vet Med. 2004:51:374-9.

24. De Silva M, Carvalho SM, Wisplinghoff H, Hall GO, Tallent S, Wallace S, et al. Clonal spread of methicillin resistant Staphylococcus aureus in a large geographic area of the United States. J Hosp Infect. 2003;53:103-10.

25. Sori H, Zerihun A, Abdicho S. Dairy cattle mastitis in and around Sebeta, Ethiopia. J Appl Vet Med. 2005;3:1525-30.

26. Hailemariam M, Shibeshi W, Molla B, Moges A, Kiros T. Antimicrobial susceptibility profile of mastitis isolates from cows in three major Ethiopian dairies. Rev Med Vet. 2005;176(7):391-4.

27. Lee J, Jeong J, Park Y, Choi S, Kim Y, Chae J, et al. Evaluation of the methicillin resistant Staphylococcus aureus (MRSA) screen latex agglutination test for detection of MRSA of animal origin. J Clin Microbiol. 2004:42:2780-2.

28. Asao T, Kumeda Y, Kawai T, Shibata T, Oda H, Haruki K, et al. An extensive outbreak of staphylococcal food poisoning due to low-fat milk in Japan: estimation of enterotoxin $A$ in the incriminated milk and powdered skim milk. Epidemiol Infect. 2003;130:33-40.

29. Schmidt T, Kock MM, Ehlers MM. Diversity and antimicrobial susceptibility profiling of staphylococci isolated from bovine mastitis cases and close contacts. J Dairy Sci. 2015:98(9):6256-69.

30. Beyene T, Endalamaw D, Tolossa Y, Feyisa A. Evaluation of rational use of veterinary drugs especially antimicrobials and anthelmintics in Bishoftu Central Ethiopia. BMC Res Notes. 2015:8(1):482

31. Tessema FA, Duguma R, Beyene T, Bihonegn A, Worku T, Adugna B, et al. Drug resistance pattern of Staphylococcus in poultry in Central and Southern Ethiopia. Global J Sci Front Res. 2016;16(2):31-6.

32. Abunna F, Bedasa M, Beyene T, Ayana D, Mamo B, Duguma R. Salmonella: isolation and antimicrobial susceptibility tests on isolates collected from poultry farms in and around Modjo, Central Oromia, and Ethiopia. JAPSC. 2016:5(2):21-35.

33. Beyene T, Yibeltie H, Chebo B, Abunna F, Beyi AF, Mammo B, Ayana D, Duguma R. Identification and antimicrobial susceptibility profile of salmonella isolated from selected dairy farms, abattoir and humans at Asella town, Ethiopia. J Vet Sci Technol. 2016;7(3):320.

34. CSA (Central Statistical Authority). Statistical abstract. Federal Democratic Republic of Ethiopia; 2006.

35. ISO 6888-3:2003. Microbiology of food and animal feeding stuffs horizontal method for the detection and identification of Staphylococci. Part 3. Geneva, Switzerland. J Food Microbiol. 2003;64:361-66. 
36. CLSI. Performance standards for antimicrobial disk and dilution susceptibility tests for bacteria isolated from animals. Clin Lab Stand Inst. 2008;28:M31-3.

37. Normanno G, LaSalandra G, Dambroise A, Quaglia N, Corrente M, Parisi A, et al. Occurrence, characterization for enterotoxigenic Staphylococcus aureus isolated from meat and dairy product. J Food Microbiol. 2007:115:290-6.

38. Morgenstern M, Erichsen C, Hackl S, Mily J, Militz M, Friederichs J, et al. Antibiotic resistance of commensal Staphylococcus aureus and coagulase-negative staphylococci in an international cohort of surgeons: a prospective point-prevalence study. PLoS ONE. 2016;11(2):e0148437.

39. Getaneh AM, Gebremedhin EZ. Meta-analysis of the prevalence of mastitis and associated risk factors in dairy cattle in Ethiopia. Trop Anim Health Prod. 2017. doi:10.1007/s11250-017-1246-3.

40. Anderson K, Pritchard D. An update on Staphylococcus aureus mastitis. 4th ed. San Francisco: Benjamin/Cummings Publishing Company; 2008. p. 38.

41. Rowe J. Milk quality and mastitis. Small ruminant for mixed practitioner. Western Veterinary Conference, Lasvagas; 1999. pp. 152-6.

42. Haileselassie M, Taddele H, Adhana K, Kalayou S. Food safety knowledge and practices of abattoir and butchery shops and the microbial profile of meat in Mekelle City, Ethiopia. Asian Pac J Trop Biomed. 2013;3(5):407-12.

43. Fluit AC. Livestock-associated Staphylococcus aureus. Clin Microbiol Infect. 2012;18(8):735-44.

44. Verkade E, Kluytmans J. Livestock-associated Staphylococcus aureus CC398: animal reservoirs and human infections. Infect Genet Evol. 2014:21:523-30.

45. Fitzgerald JR. Livestock-associated Staphylococcus aureus: origin, evolution and public health threat. Trends Microbiol. 2012;20(4):192-8.

46. Sakwinska O, Giddey M, Moreillon M, Morisset D, Waldvogel A, Moreillon P. Staphylococcus aureus host range and human-bovine host shift. Appl Environ Microbiol. 2011;77(17):5908-15.

47. Ma Y, Chang SK, Chou CC. Characterization of bacterial susceptibility isolates in sixteen dairy farms in Taiwan. J Dairy Sci. 2006;1:55-6.

48. Blaiotta G, Ercolini D, Pennacchia C, Fusco V, Casaburi A, Pepe O, Villani F. PCR detection of staphylococcal enterotoxin genes in Staphylococcus spp. strains isolated from meat and dairy products. Evidence for new variants of seG and sel in S. aureus AB-8802. J Appl Microbiol. 2004;97(4):719-30.

49. Zell C, Resch M, Rosenstein R, Albrecht T, Hertel C, Götz F. Characterization of toxin production of coagulase-negative staphylococci isolated from food and starter cultures. Int J Food Microbiol. 2008;127(3):246-51.

50. Bautista L, Gaya P, Medina M, Nunez M. A quantitative study of enterotoxin production by sheep milk Staphylococci. App Environ Microbiol. 1988:54:566-9.

51. Martın M, Fueyo J, Gonzalez M, Mendoza M. Genetic procedures for identification of enterotoxigenic strains of Staphylococcus aureus from three food poisoning outbreaks. J Food Microbiol. 2004;94:279-86.

52. Morandi S, Brasca M, Lodi R, Cremonesi P, Castiglioni B. Detection of classical enterotoxins and identification of enterotoxin genes in Staphylococcus aureus from milk and dairy products. Vet Microbiol. 2007;124:66-72.

53. Salandra G, Goffredo E, Pedarra C, Nardella M, Parisi A, Dambrosio A, et al. Occurrence, characterization and antimicrobial resistance pattern of Staphylococcus species isolated from dairy products in southern Italy. Int J Food Microbiol. 2008;9:327-60.

54. Seedy E, El-Shabrawy F, Hakim M, Dorgham A, Ata S, Nagwa S, et al. Recent techniques used for isolation and characterization of Staphylococcus aureus from mastitic cows. Am J Sci. 2010;6:1-8.

55. Jakee J, Ata S, Nagwa M, Sahar BA, Elgabry ZE, El-Said GW. Characteristics of Staphylococcus aureus strains isolated from human and animal sources. Am-Euras J Agri Environ Sci. 2008;4:221-9.

56. Jorgensen H, Mork T, Rorvik L. The occurrence of Staphylococcus aureus on a farm with small scale production of raw milk cheese. J Dairy Sci. 2005;88:3810-7.

57. Hein I, Jorgensen H, Loncarevic S, Wagner M. Quantification of Staphylococcus aureus in unpasteurized bovine and caprine milk by real-time PCR. Res Microbiol. 2005;156:554-63.
58. Bendahou A, Lebbadi M, Ennanei L, Essadqui F, Abid M. Characterization of Staphylococcus species isolated from raw milk and milk products (Iben and jben) in North Morocco. J Infect Dis Dev Ctries. 2008;2:218-25.

59. Lamprell H, Villard L, Chamba J, Beuvier E, Borges E, Maurin F, et al. Identification and biotyping of coagulase positive Staphylococci (CPS) in ripened French raw milk cheeses and its in vitro ability to produce enterotoxins. Res Vet Med. 2004;155:92-6.

60. Tsegmed U. Staphylococci isolated from raw milk of yak and cattle in Mongolia. Studies on the occurrence, characterization, detection of enterotoxin and antimicrobial susceptibility profile of the isolates. Uppsala: Swedish University of Agricultural Sciences, Master's Thesis; 2006.

61. Kloos W, Bannerman T. Update on clinical significance of coagulase negative Staphylococci. Clin Microbiol Rev. 1994;7:117-40.

62. Lourdes M, Cunha R, Sinzato Y, Silveira L. The medical significance and identification of coagulase negative Staphylococci. J Clin Microbiol. 2004;99:855-60.

63. Shah M. Molecular pathogenesis of Staphylococcus aureus and other Staphylococci. J Appl Bacteriol. 2003;59:207-21.

64. Mekuria A, Asrat D, Woldeamanuel Y, Tefera G. Identification and antimicrobial susceptibility of Staphylococcus aureus isolated from milk samples of dairy cows and nasal swabs of farm workers in selected dairy farms around Addis Ababa Ethiopia. Afr J Microbiol Res. 2013;7(27):3501-10.

65. Nihal Y, Sumru C, Sinem B. Antimicrobial resistance profile of Staphylococcus aureus isolated from clinical samples and foods of animal origin. Food Pathog Dis. 2011:8:427-31.

66. Edward M, Anna K, Michal K, Henryka L, Krystyna K. Antimicrobial susceptibility of Staphylococci isolated from mastitic cows. Bull Vet Inst. 2002;46:289-94.

67. Gentilini E, Danamiel A, Betancor M, Rebuelto M, Fermepin R, Detorrest R. Antimicrobial susceptibility of coagulase negative Staphylococci isolated from bovine mastitis in Argentina. J Dairy Sci. 2002;85:1913-7.

68. Sori T, Hussien J, Bitew M. Prevalence and susceptibility assay of Staphylococcus aureus isolated from bovine mastitis in dairy farms in Jimma town South West Ethiopia. J Anim Vet Adv. 2011;10:745-9.

69. Landin H. Treatment of mastitis in Swedish dairy production. Svensk Vet. 2006:58:19-25 (in Swedish with English summary).

70. Gooraninejad S, Ghorbanpoor M, Salati A. Antibiotic susceptibility of Staphylococci isolated from bovine sub-clinical mastitis. Pak J Biol Sci. 2007;10:2781-3.

71. Myllys V, Asplund K, Brofeld E, Koski HV, Buzalski HT. Bovine mastitis in Finland in 1988 and 1995. Changes in prevalence and antimicrobial resistance. Acta Vet Scand. 1998;39:119-26.

72. Adesiyun A. Characteristics of Staphylococcus aureus strains isolated from bovine mastitic milk: bacteriophage and antimicrobial agent susceptibility and enterotoxigenecity. J Vet Med. 1994;42:129-39.

73. Pereira V, Lopes C, Castro A, Silva J, Gibbs P, Teixeira P. Characterization for enterotoxins production, virulence factors and antibiotic susceptibility of Staphylococcus aureus isolates from various food in Portugal. Food Microbiol. 2009:26:278-82.

74. Jaims E, Montros L, Renata D. Epidemiology of drug resistance; the case of Staphylococcus aureus and coagulase negative Staphylococci infections. Salud Pub Mex. 2002;44:108-12.

75. Moon J, Lee A, Jaw S. Comparison of antibiogram, staphylococcal enterotoxin productivity, and coagulase genotypes among Staphylococcus aureus isolated from animal and vegetable sources in Korea. J Food Prot. 2007;70:2541-8.

76. Chao G, Zhou X, Jiao X. Prevalence and antimicrobial resistance of food borne pathogens isolated from food products in China. Food borne Pathog Dis. 2007:4:277-84.

77. Balta B, Derbie F. Nasal carriage of methicillin resistant Staphylococcus aureus strains among inpatients of Jimma hospital, South Western Ethiopia. Ethiop J Health Sci. 2003;13:30-40. 